\title{
Brief review analytical methods for the determination of glyphosate
}

\begin{abstract}
The quantification of levels of biological samples can be an important tool in human biomonitoring and can provide reliable estimates of the levels of human exposure to products of substances used in plant protection. Due to this, it is emphasized the importance in developing methods that are effective and quick to determine andquantify these molecules of interest. Thus, it performed a critical review of literature and data comparison studies already available on the development of analytical methods for determining the pesticide glyphosate.
\end{abstract}

Keywords: glyphosate, determination, chromatography, pesticides, analytical methodologies
Volume 4 Issue | - 2018

\author{
Melo KG,' De Nucci G,' Trape AZ,' \\ Jacobucci SRF,' Garlipp CR, ${ }^{2}$ Rosa PCP \\ 'Department of Pharmacology, University of Campinas, Brazil \\ ${ }^{2}$ Department of Public Health and Pathology, University of \\ Campinas, Brazil
}

\begin{abstract}
Correspondence: Paulo César Pires Rosa, PhD Department of Pharmacology, University of Campinas (Unicamp), I 3083-887 Campinas (São Paulo), Brazil,Tel +551935219585,
\end{abstract}

Email pcpr27@gmail.com, paulo.rosa@fcm.unicamp.br

Received: February 12, 2018 | Published: February 19, 2018

\begin{abstract}
Abbreviations: HPLC, high-performance liquid chromatography; GC, gas chromatography; LC, liquid chromatography; AMPA, aminomethylphosphonic acid

\section{Introduction}

are common in determining glyphosate, although their properties hinder this process, necessitating often derivatization reactions so that there is a response from chromatographic techniques such as gas chromatography (GC). ${ }^{18-22}$ Liquid Chromatography (LC) ${ }^{23-25}$ and equipment with UV detection-vis. ${ }^{26-28}$
\end{abstract}

Glyphosate is a non-selective herbicide widely used in agriculture, which accounts for over $60 \%$ in the global market, providing a wide spectrum of action which enables an optimal control danin has plants. ${ }^{1-4}$ Besides, this pesticide has low acute oral toxicity when compared to other herbicidas. ${ }^{5-7}$ It is known that pesticide residues are widely used in chromatographic methods for quantifying the target analyte. However, many pesticides have high polarity, such as glyphosate, making it difficult to determine. Therefore, in many cases, it is used derivatization of these compounds, in order to make them suitable for a particular method in determining analítico. ${ }^{8-12}$ It is noteworthy that even with derivatization often these residues require significant laboratory resources, as well as treatment processes of long, complex and expensive samples. So there is a clear need to develop simple, fast and effective methodologies that are able to determine and analyze high polarity pesticides. ${ }^{13,14}$ The aim of this study was to develop brief review of the main analytical methodologies available in the analytical determination of glyphosate pesticide by chromatographic methods.

\section{Analytical methodologies}

Glyphosate has high polarity with the added feature of forming ionic species and no chromophores groups, determine their ends become more complexa. ${ }^{29}$ Thus, the determination of this pesticide often requires additional processes that may allow quantification by chromatographic methods. It is known that there are several studies on the determination of pesticide glyphosate in various types of samples, such as urine and human blood grain in breast milk and água. ${ }^{15-17}$ However, some of these studies vary widely depending on the sensitivity and recovery of the chromatographic unit and sample processing.

\section{High-performance liquid chromatography (HPLC)}

In general, the development of analytical methods for HPLC

\section{Determination of glyphosate by HPLC with fluorescence detection}

It is known that glyphosate from determinations of fluorescence detectors have a high sensitivity and selectivity when compared to analysis by ultraviolet. Therefore, by derivatization procedures of this compound, it is possible to make it fluorescent allowing a proper determination. Another alternative to glyphosate analysis was performed by Sancho et al., ${ }^{8}$ which held a simultaneous determination of glufosinate, glyphosate and AMPA samples in water using a C18 column for better efficiencies for the separation of analyte, coupled with an amino second chromatographic column of anion exchange for the separation of derivative compounds. In tentative to improve the sensitivity, the authors attempted to decrease the detection limit for the unit of $\mathrm{mg} / \mathrm{L}$ concentrating a given volume by evaporation of water sample. However, this step resulted in lower recoveries than 20 and $30 \%$ of glyphosate and AMPA, respectively. However, they investigated the lowering of the detection limit for application of method focusing on individual determination for each analyte obtained where higher recoveries than $95 \%$, In one of their studies Mallat \& Barceló ${ }^{29}$ performed studies to determine and glyphosate degradation and its major metabolite aminomethylphosphonic acid (AMPA) in water samples from their derivatization using o-phthalaldehyde (OPA) postcolumn reaction with wavelengths of excitation and emission $330 \mathrm{~nm}$ and $465 \mathrm{~nm}$, respectively, and ion exchange chromatographic column $150 \times 4 \mathrm{~mm}$ in $\mathrm{K}^{+}$form. His studies showed that $83 \%$ recoveries for glyphosate and AMPA to $90 \%$. Another derivatizing widely described in the literature is the fluorrenilmetilloxicarbonilo chloride ( $\mathrm{Fmoc}-\mathrm{Cl})$. Hogendoorn et al., ${ }^{27}$ determined glyphosate in cereal samples per precolumn derivatization with FMOC-CL. For the HPLC analyzes was used chromatographic column 30x4.6mm C18 Hypersil ODS $5 \mu \mathrm{m}$ DI and adsorption column $5 \mu \mathrm{m} 250 \times 4.6 \mathrm{~mm}$ DI NH2. Recoveries between 74 and $86 \%$ were obtained. It was given a limit of detection (LOD) of 2 and $4 \mathrm{ppb}$ to glyphosate and AMPA, respectively. 


\section{Determination of glyphosate by HPLC with detection by UV-vis}

Catrinck et al., ${ }^{30}$ sought in his optimization studies a quick, easy and efficient technique for derivation of glyphosate and AMPA by using FMOC-Cl analyzed by UV- vis. The reaction of derivatization with FMOC-CL excellent proved to be an alternative due to the high sensitivity this compound in the ultraviolet region. Moreover, the authors of this paper investigated the occurrence and increased sensitivity of this reaction from parameters such as spectral behavior derivatization effect of the concentration of borate buffer effect of homogenization time, effect of reaction time and effect solvent wash. Overall, the results showed that the optimal homogenization conditions were vortexed for 5 minutes using borate buffer $200 \mathrm{mmol} / \mathrm{L}$ and FMOC-CL 500mg/L.

\section{Determination of glyphosate by HPLC coupled with mass spectrometry (MS / MS)}

An analytical method was developed for the determination of glyphosate and AMPA in sewage samples. The method involving an alkaline extraction and purification sludge of a sufficiently strong anion exchange resin. Thus, while the remaining analytes fixed by ionic interactions, derivatization was performed by FMOC-CL. For the process of extraction, solid phase extraction cartridges were used (SPE) Oasis HLB. The analysis by HPLC-MS / MS was performed in positive mode obtaining average values of $70 \%$ glyphosate and AMPA recovery. In the same study, they were obtained LD 20 and 35 and $30 \mathrm{ppb} 50 \mathrm{ppb}$ and LQ of glyphosate and AMPA respectivamente. ${ }^{27}$

Cabrices et al., ${ }^{33}$ also used by SPE extraction cartridges. Their method was able to evaluate concentration levels of up to $10 \mathrm{mg} / \mathrm{kg}$ showing excellent reproducibility and values within the $\pm 20 \%$ range. Moreover, we used the extraction method Quick Polar Pesticides (QuPPe) that has been compared to the results of the recovery of non-QuPPe extraction. Overall recoveries were between QuPPe using $70-120 \%$ for both analytes (glyphosate and AMPA receptors) in the array. However, the extraction recovery using non-QuPPe extraction were lower in all cases. Baker et al. ${ }^{39}$ Determined glyphosate and other pesticide residues by HPLC-MS/MS without derivatization evaluating various chromatographic columns and mobile phases, and evaluate the MS / MS parameters. For primero method, a ZIC-HILIC chromatography column was used $(100 \times 2.1 \mathrm{~mm}, 3,5 \mu \mathrm{m})$ and mobile phase with ammonium formate in water $20 \mathrm{mmol} / \mathrm{L}$ with $0.3 \%$ formic acid and acetonitrile to evaluate the pesticides amitrole, chlormequat, daminozide, diquat, kasugamycin, mepiquat, paraquat and trimesium. The presented method was linear with $\mathrm{R}^{2}>0.998$ at a concentration range from 0.005 to $0.2 \mathrm{mg} / \mathrm{kg}$ (5-200ppb). The second method used a CMP Hypercarb column $(100 \mathrm{~mm} \times 2.1 \mathrm{~mm}, 5 \mu \mathrm{m})$, mobile phase water with $1 \%$ acetic acid and methanol with $1 \%$ acetic acid to determine the pesticide glufosinate, glyphosate, ethephon, fosetyl aluminum, maleic hydrazide, perchlorate, ETU, OCT and nicotine. All analytes in the method 2 showed excellent linearity with $\mathrm{R}^{2}>0.999$.

\section{Gas chromatography (GC)}

Also widely used for the determination of glyphosate, the technique for quantification by $\mathrm{GC}$ requires derivatization usually involves mixing two compounds; trifluoroacetic anhydride (TFAA) and trifluoroethanol (TFE) in excess. These compounds are known to convert glyphosate to AMPA and only a single reaction step, which derivatives are sufficiently volatile for GC analysis / MS..$^{30-40}$

\section{Determination of glyphosate by GC coupled to mass spectrometry (MS/MS)}

Papers involved Development and validation of two independent analytical principles for the quantification of glyphosate in breast milk samples. The aim was to determine the most sensitive. One of the methods used HPLC-MS / MS without derivatization. The second is based on derivatization with TFAA and heptafluorobutanol (HFB) followed by GC-MS / MS for the determination of glyphosate. The results of this study showed recoveries higher for the method HPLC-MS / MS who were about 91 to $94 \%$ (at concentrations of 1 and $5 \mathrm{ng} / \mathrm{ml}$ glyphosate in matrix, respectively), whereas GC-MS / MS the recovery remained values in the range $83-84 \%$ at the same concentrations. The LQ for both methods was $1 \mathrm{ng} / \mathrm{ml}$. Besides that, the method presented by GC was much slower due to the need of additional steps for removal of excess derivatizing, making this method more complicated and exhaustive. ${ }^{4}$ Therefore, it is important to consider the derivatization or not an analyte. In another approach, a method was developed using the same aforementioned derivatizing which demonstrated a $0,05 \mu \mathrm{gQ} / \mathrm{L}$ and average recovery values of 93 and $95 \%$ for glyphosate and AMPA, respectively. The separation of the analytes was performed with a $30 \mathrm{mmx} 0.25 \mathrm{~mm}$ id column with film thickness $5 \%$ phenyl and $95 \%$ dimetilpolisiloxano. ${ }^{10}$

\section{Determination of glyphosate by GC with detection by flame photometry (DFC)}

We conducted studies for simultaneous determination of glyphosate, glufosinate and AMPA receptors in environmental and food samples. The extraction procedure was done with water or sodium hydroxide solution, converting these compounds into nisopropoxycarbonyl. The method used a capillary column DB-1701. This method was applied to samples of the river water, soil and carrot. The recovery of these compounds in the samples was $91106 \% .{ }^{23}$

\section{Conclusion}

While there are several and distinct chromatographic techniques for the determination of glyphosate, it is essential to find the most appropriate considering the peculiarities that this pesticide presents. The most common and widely utilize technique is HPLC, although often require derivatization to improve the sensitivity and selectivity, including detectors for UV-vis and fluorescence. Furthermore, these methods have higher recovery values when compared to other methods.

It was also found that determinations by $\mathrm{CG}$ despite having good sensitivity could become more complex due to the need to derivatize glyphosate in order to make it volatile.

\section{Acknowledgements}

This study was financed in part by the Coordenação de Aperfeiçoamento de Pessoal de Nível Superior - Brasil (CAPES) - Finance Code 001 and Research and Extension (FAEPEX-UNICAMP). The authors thank to Prof. Angelo Zanaga Trapé, Siomara Regina Jacobucci and Prof. Célia R. Garlipp from the Laboratory of Toxicology and Biological 
Samples / FCM-Unicamp for the partnership and contribution during several stages of the project.

\section{Conflict of interest}

The author declares no conflict of interest.

\section{References}

1. Zouaoui K, Dulaurent S, Gaulier JM, et al. Determination of glyphosate and AMPA in blood and urine $\mathrm{f}$ from humans: about 13 cases of acute intoxication. Forensic Sci Int. 2013;226(3):20-25.

2. Velini ED, Alves E, Godoy MC, et al. Glyphosate applied at low doses can stimulate plant growth. Pest Manag Sci. 2008;64(4):489-496.

3. Trent, T, Jordan R. Determination of highly polar residues in food Pesticides of plant origin, by an automated QuPPe solution. The application note, 2014. p. 2-4.

4. Steinborn A, Alder L, Michalski B, et al. Glyphosate Determination of Levels in Breast Milk Samples from Germany by LC-MS / MS and GCMS / MS. J Agric Food Chem. 2016;64:1414-1421.

5. Souza MT, Matta MHR, Montagner E, et al. Study of recovery and stability of derivatized gliphosate and AMPA in soil using national resins. Chemistry new. 2006;29(6):1372-1376.

6. Shummer W, Millet M, Delhomme O, et al. Comparison of MTBSTFA and in BSTFA derivatization reactions of polar compounds prior to GC MS analysis. Talanta. 2009;77(4):1473-1482.

7. Lukaszewski T. The extraction and analysis of quaternary ammonium compounds in biological materials by GC and GC/ MS. J Anal Toxicol. 1985;9(3):101-108.

8. Sancho JV, Hernandez M, Lopez FJ, et al. Reapid determination of glufosinate, glyphosate and aminomethylphosphonic acid in environmental water samples using labeling and Fluorogenic precolun column liquid chromatography coupled. J Chromatography. $1996 ; 1737: 75-83$.

9. Patsias J, Papadopoulou A, Papadopoulou-Mourkidou E. Automated trace level determination of glyphosate and aminomethyl phosphonic acid in water online by anion- exchange solid-phase extraction fllowed by cation-exchange liquid chromatography and post-column derivatizations. J Chromatogr. 2001;932(1-2):83-90.

10. Royer T, Beguin S, Tabet JC, et al. Determination of glyphosate and aminomethylphosphonic acid residues in water by gas chromatography tandem mass spectrometry with ion exchange resin after purification and derivatization. Application on vegetable Matrixes. J Anal Chem. 2000; $72(16): 3826-3832$

11. Roy DN, Konar SK. Development of the analytical method for the determination of glyphosate and (aminomethyl)-phosphonic acid residues in soil by nitrogen-selective gas chromatography. J Agric Food Chem. 1989;37(2):441-443.

12. Roca M, Yusa V, Leon N, et al. Comprehensive Analytical strategy for biomonitoring of pesticides in urine by liquid chromatographyhigh resolution Orbitrap mass spectrometry. J Chromatography. 2014;1374:66-76.

13. About OD, Friggi CA, Adaime MB, et al. QuEChERS-A modern sample preparation method for pesticide multiresidue determinationin food by chromatographic methods coupled to mass spectrometry. Quim New. 2009;32(6):51-64.

14. Possidónio OA, Roberts CT, Brito N, et al. Methods of extraction and determination of glyphosate: Quick review. Quim New. 2002;25:420 428
15. Possidónio OA, Roberts CT, Brito N, et al. Glyphosate: properties, toxicity, uses and legislation. Quim New. 2002;25(4):589- 593.

16. Pineiro M, Cold CF, Gramacho SA. Gas chromatography-mass spectrometry and microwave-assisted identification of derivatization is glucose isomers: experience for post-graduate teaching of analysis and characterization of organic compounds. Quím Nova. 2014;37(1):176180 .

17. Niemann L, Sieke C, Pfiel R, et al. A critical review of glyphosate findings in human urine samples and exposure on the comparation with Consumers and operators. Journal für Verbraucherschutz und Lebensmittelsicherheit. 2015;10(1):3-12.

18. Moye HA, Deyrup CL. Single-step derivatization method for the gas chromatographic analysis and metabolite of the herbicide. J Agric Food Chem. 1984;32(2):192-195.

19. Martínez VJL, Arrebola LFJ, Gonzales RMJ, et al. Validation of a gas chromatography / triple quadrupole mass spectrometry based method for the quantification of pesticides in food commodities. Rapid Commun Mass Spectrom. 2006;20(3):365-375.

20. Lovdahl MJ, Pietrzyk DJ. Liquid Chromatography and Postcolumn Indirect Detection of Glyphosate. J Chromatogr. 1992;602(2):197-204.

21. Lin $\mathrm{CH}$, Yan PV, Kumar HP. Determination of pyrethroid metabolites in human urine using liquid-phase microextraction coupled in syringe Followed by derivatization gas chromatography/electron capture detection. Anal Bional Chem. 2001;401(3):221-233.

22. Lehotay SJ, Lightfield AR, Fetcho-Harman J, et al. Analysis of Pesticide Residues in Eggs by Direct Sample Introduction / Gas Chromatography / Tandem Mass Spectrometry. J Agric Food Chem. 2001;49(10):45894596.

23. Kataoka H, Ryu S, Sakiyama N, et al. Simple and rapid determination of the herbicides glufosinate and glyphosate in river water, soil and carrot samples by gas chromatography with flame photometric detection. $J$ Chromatogr. 1996;726(2):253-258.

24. Helle N, Chmelka F. Automated derivatization, cleanup and LC-MS-MS Determination of glyphosate and AMPA. Germany: The Column; 2013.

25. Grieves N, Wynne P, Hewetson J, et al. The application of LC-UFMSMS to the analysis of pesticides in negative ion ESI residues. Australia; 2007.

26. Ghanem A, Bados P, Kerhoas L, et al. Glyphosate and AMPA analysis in sewage sludge by LC-ESI-MS/MS after FMOC derivatization on strong anion-exchange resin as solid support. Anal Chem. 2007;79(10):3794 3801 .

27. Hogendoorn EA, Ossendrijver FM, Dijkman E, et al. Rapid determination of glyphosate in cereal samples by means of precolumn derivatisation with 9-fluorenylmethyl chloroformate and-column liquid chromatography coupled with fluorescence detection. J Chromatograph. 1999;833(1):67-73.

28. Deyrup Cl, Chang S, Weintraub RA, et al. Simultaneous esterification and acylation of pesticides for analysis by gas chromatography. Od derivatization and glyphosate (aminomethyl) phosphoni anhydrides with alcohols fluorinated perfluorinated. 1985:944-947.

29. Barcelo D, Mallat E. Analysis and study of degradation of glyphosate and aminomethylphosphonic acid in natural waters by means of ionexchange polymeric and solid- phase extraction columns Followed by ion chromatography post-column derivatization with fluorescence detection. J Chromatogr. 1998;823(2):129-136.

30. Catrinck CPG, Dias A, Aguiar MCS, et al. A Simple and Efficient Method for derivatization of glyphosate and AMPA Using 9-Fluorenylmethyl 
chloroformate and spectrophotometric Analysis. J Braz Chem Soc. 2014;25(7):1194-1199.

31. Chamberlain K, Evans AA, Bromilow HR. 1- Octanol / Water Partition Coefficient (Kow) and pK is Ionisable Pesticides Measured by Method Metric pH Keith. Pestic Sci. 1996;47(3):265-271.

32. Carvalho LB, Schmit R, Agostineto MC, et al. Synergism of Mixtures of glyphosate and PROTOX inhibitor herbicides for morning-glory control. Agostineto. 2015;15(1):2-8.

33. Cabrices OG, Schreiber A. Automated derivatization, Cleanup SPE and LC/MS/MS Determination of glyphosate and Other Polar Pesticides. Anal Chem. 2007;79:3794-3801.

34. Sheep FF, Pignati W, Rigotto RM, et al. Dossiê ABRASCO-A warning about the impacts of pesticides on health. Part 1-Agrochemicals, Food and Nutritional Security and Health. Rio de Janeiro: ABRASCO; 2012.

35. Botta F, Laviso G, Couturier G, et al. Transfer of glyphosate and AMPA its degradate to surfacewaters through urban sewerage systems. Chemosphere. 2009;77(1):133-139.
36. Botero-Coy AM, Sancho N, Hernandez F. Direct liquid chromatographytandem mass spectrometry determination of underivatized glyphosate in rice, maize and soybean. J Chromatography. 2013;1313:157-165.

37. Börjesson E, Torstensson L. New Methods for determination of glyphosate and aminomethyl) phosphonic acid in water and soil. $J$ Chromatograph. 2000;886(1-2):207-216.

38. Baylis AD. Why glyphosate herbicide is a global: strengths, Weaknesses and prospects. Pest Manag Sci. 2000;56(4):299-308.

39. Baker DR, Levi M, Capodanno E. Highly multi-polar pesticide residue in food safety by LC-MS / MS. UK; 2015.

40. Anastassiades M, Kolberg DI, Eichhorn E, et al. Quick Method for the Analysis of Highly Polar Residues of numerous Pesticides in Foods of Plant Origin Involving Simultaneous Extraction with Methanol and LC-MS/MS Determination (QuPPe-Method) is Laboratory pesticides Requiring Single Residue Methods (RCM-EURL). Germany; 2012. 